Cahiers $d u$ MONDE RUSSE

\section{Cahiers du monde russe}

Russie - Empire russe - Union soviétique et États indépendants

$55 / 3-4 \mid 2014$

Varia

\title{
Nanci Adler, Keeping faith with the Party, Communist believers return from the Gulag
}

\section{Marc Elie}

\section{(2) OpenEdition}

\section{Journals}

Édition électronique

URL : http://journals.openedition.org/monderusse/8078

DOI : $10.4000 /$ monderusse. 8078

ISSN : $1777-5388$

\section{Éditeur}

Éditions de l'EHESS

\section{Édition imprimée}

Date de publication : 1 juillet 2014

Pagination : 425-428

ISBN : 978-2-7132-2441-6

ISSN : $1252-6576$

\section{Référence électronique}

Marc Elie, "Nanci Adler, Keeping faith with the Party, Communist believers return from the Gulag », Cahiers du monde russe [En ligne], 55/3-4 | 2014, mis en ligne le 13 avril 2015, Consulté le 24 septembre 2020. URL : http://journals.openedition.org/monderusse/8078 ; DOI : https://doi.org/ 10.4000/monderusse.8078

Ce document a été généré automatiquement le 24 septembre 2020.

(c) École des hautes études en sciences sociales 


\title{
Nanci Adler, Keeping faith with the Party, Communist believers return from the Gulag
}

\author{
Marc Elie
}

\section{RÉFÉRENCE}

Nanci ADLER, Keeping faith with the Party, Communist believers return from the Gulag, Bloomington : Indiana University Press, 2012, 237 p.

1 «Coupe la forêt-volent les copeaux» (лЕс РуБят - ЩЕпкИ лЕтят). Ce proverbe classique dans la littérature concentrationnaire soviétique suscite chez Nanci Adler une interrogation essentielle (p. 156) : Pourquoi de nombreux ex-communistes n'ont-ils pas mis en doute leur fidélité au parti malgré leur expérience parfois très longue (jusqu’à une vingtaine d'années) dans les camps et en exil ? Pourquoi se sont-ils revendiqués copeaux dans la construction d'un projet plus grand qu'eux, justifiant les injustices et les souffrances au nom de l'idéal communiste?

2 Adler, déjà auteur de deux livres sur les anciens détenus et la mémoire du Goulag, consacre ce troisième ouvrage à ces communistes fervents, envers et contre tout, que peignent Solženicyn et Šalamov : dans les camps, ces fidèles excusaient leur arrestation (nécessitée par un projet immense), mettaient hors de cause le parti et Stalin (qui n'étaient pas au courant) et rejetaient la faute sur l'ennemi infiltré dans la police (p. 12). Une fois libérés, nombre d'entre eux cherchèrent à réintégrer le parti et ne questionnèrent pas la responsabilité du régime. Adler ouvre ainsi un fascinant champ d'étude de l'adhésion au projet communiste dans le second vingtième siècle soviétique, celui qui s'ouvre à la mort de Stalin, et qu'on désigne souvent comme une périodeaprès un court dégel-de désengagement idéologique et de cynisme social. Adler s'appuie sur une riche documentation. Elle a conduit des entretiens et interrogé par questionnaire d'anciens détenus et leurs descendants. Elle tire profit des formidables 
archives de Memorial à Moscou, qui contiennent des centaines de journaux intimes et Mémoires inédits. Enfin, elle exploite le fonds 560 de RGASPI qui conserve les ego-documents de communistes s'exprimant sur la dénonciation du «culte de la personnalité » dans les années 1950-1960.

3 La direction politique poststalinienne a permis aux communistes de garder ou retrouver confiance dans le parti et dans ses idéaux en l'innocentant lors de la condamnation du « culte de la personnalité » au congrès de 1956. Plus fort, elle a fait du parti la victime principale de Stalin. Ainsi, « les victimes n'étaient plus coupables, et le parti ne l'avait jamais été » (p. 46).

4 Le parti avait triomphé du culte de Stalin et de l'ennemi infestant la police. Cette nouvelle narration sortait les anciens communistes d'un dilemme qu'un réhabilité définissait ainsi : "admettre ma culpabilité pour des crimes que je n'avais pas commis aurait été infondé, dire qu'on m'avait condamné pour rien et exclu injustement du parti aurait pu être considéré calomnie » (p. 14). Désormais, les réhabilités étaient mis hors de cause : ils n'avaient plus à mentionner leur condamnation dans les formulaires administratifs. Surtout, leurs années de Goulag prenaient sens : comptées dans leur ancienneté au parti et à leur travail, elles étaient reconnues comme travail honnête dans la construction du communisme, et non pas comme labeur forcé, inutile et absurde. À la suite de Miriam Dobson, Adler montre que les anciens détenus se sont saisis de cette opportunité pour interpréter et écrire leur vie dans les nouveaux cadres définis par la politique de réhabilitation. "Modelant un passé utile» (p. 83), ils ont inscrit leur histoire personnelle dans le récit salvateur de l'histoire du parti dressé aux $\mathrm{XX}^{\mathrm{e}}$ et XXII ${ }^{\mathrm{e}}$ congrès (p. 35-36, 74). En acceptant ce récit, les communistes fervents s'interdisaient la réflexion sur les responsabilités dans les répressions.

5 Après tout, dans la " société fermée » qu'était la société soviétique, le système politique n'y avait aucun compte à rendre aux citoyens, c'étaient à eux de s'adapter. Entrer au parti communiste était une étape nécessaire pour faire carrière. On n'a donc pas de mal à comprendre que les anciens détenus, au bas de l'échelle sociale, aient cherché à y entrer ou rentrer: pour accéder à des emplois mieux payés, pour obtenir un appartement dans une ville à "réglementation spéciale ", pour bénéficier d'une pension personnelle à laquelle les vieux bolcheviks pouvaient prétendre. Ces avantages importants n'étaient accessibles qu'à ceux qui (ré)intégraient l'élite. En entrant au parti, les réhabilités pouvaient espérer protéger leurs proches et eux-mêmes des discriminations officielles et latentes dont ils étaient victimes. Adler ne manque jamais de rappeler que des calculs matériels, professionnels et sociaux codéterminaient souvent l'adhésion au projet communiste chez les réhabilités. Mais elle ne s'en satisfait pas et veut aller au-delà des explications de l'histoire sociale. Elle cherche ainsi à expliquer moins les motivations des ex-membres pour une réintégration au parti que leur adhésion sincère et intacte à la cause communiste malgré les souffrances et humiliations subies dans les camps, la destruction de leur famille et de leurs amis par la faim, le peloton d'exécution ou l'épuisement.

6 À un dialogue avec ceux des chercheurs qui discernent une "subjectivité soviétique " (Halfin, p. 55-57), Adler préfère les emprunts à la psychologie sociale pour rendre compte de l'adhésion idéologique. Or, si on admet aisément que l'appartenance au PC donnait à ses membres un sentiment de sécurité et de communauté et leur apportait des réponses aux questions sur le sens de la vie (p.27), les explications psychosociologiques mobilisées par Adler - «dissonance cognitive», défense 
psychologique et lien traumatique - ne rendent guère service à l'analyse. Ainsi l'explication par la dissonance collective à laquelle les communistes auraient cherché à échapper ou qu'ils auraient cherché à rendre acceptable, souffre d'un problème méthodologique : elle présuppose une position surplombante (celle du chercheur) qui attribue aux événements leur caractère de preuve objective contredisant la croyance. Si chez Leon Festinger la fin du monde n'avait effectivement pas lieu, forçant donc les apôtres d'une apocalypse imminente à rétablir la cohérence de leur foi en manipulant les faits, les événements du dégel n'ont pas ce caractère d'évidence et sont soumis à diverses interprétations. Adler voit un paradoxe en ce que « la croyance dans le parti persistait malgré l'évidence de preuves contraires» (p. 11). Mais, pour de nombreux communistes, l'action du parti n'allait-elle pas bien plutôt dans le sens de la croyance sincère? Le parti n'avait-il pas condamné les crimes commis sous Stalin et rétabli ses victimes, ne s'était-il pas engagé à renouer avec le Lenin?

7 Dans la même veine psychosociologique, Adler traite le communisme comme une religion et même une nouvelle religion remplaçant les religions traditionnelles (p. 31). Dans l'épilogue, la religion est heureusement ravalée au rang de simple métaphore (p. 174-175). Dans tous les cas, l'apport est faible: la recherche d'un soutien communautaire et la quête de sens sont caractéristiques des systèmes de croyance en général, et non de la seule croyance religieuse, comme le souligne d'ailleurs Adler.

Adler est la plus convaincante quand elle délaisse les explications psychosociologiques et procède à l'analyse fine des entretiens. Ainsi, elle croise une multitude d'explications coupées au plus juste des déclarations des intéressés : le patriotisme (particulièrement renforcé par la guerre), le sacrifice librement accepté qui magnifie les souffrances, l'acquiescement à la nécessité historique, la volonté de protéger ses convictions ; mais aussi l'intimidation, l'endoctrinement, le sentiment d'impuissance, bref les contraintes d'une société fermée, dans laquelle « le pouvoir d'imposer l'obéissance peut devenir le pouvoir d'imposer les explications » (p. 63).

9 L'une des principales forces de l'ouvrage est qu'il englobe aussi les années 1980 et 1990. Cette large focale chronologique fait apparaître un phénomène inattendu: les fluctuations idéologiques de la direction politique sous Brežnev et Gorbačev, entre restalinisation larvée et critique intégrale du système, ont été une sérieuse épreuve pour la foi des plus fidèles, qui l'avaient conservée dans les camps et pendant la dénonciation de Stalin par Hruščev (p. 138-141, 157, 162). Dans ces moments-là certains communistes convaincus se détournent du parti soit parce que le consensus historique khrouchtchévien est attaqué, soit parce que la culpabilité unique de Stalin et de ses sbires est mise en doute, et que Lenin à son tour est démythifié.

Dans ce texte d'apparence décousue, Adler donne à voir « l'âme bolchevique » à travers de saisissants portraits de communistes fervents, dont certains luttaient encore à la fin des années 1980 pour leur réintégration au parti. De nouvelles questions naissent à la lecture : qu'est-ce qui, dans le fonctionnement du parti, donnait à ses membres un si fort sentiment d'appartenance? En quoi la formation des communistes les prédisposait-elle à accepter de manière inconditionnelle la ligne du parti et à se sacrifier pour elle? D'où vient l'idée largement répandue chez les anciens communistes que rentrer au parti après leur libération est un devoir ? C'est finalement à une analyse $\mathrm{du}$ parti comme matrice sociale et émotionnelle qu'appelle Adler. Un fructueux dialogue pourrait s'engager avec Malte Griesse et d'autres sur la subjectivité en URSS. 
11 Adler cite fort à propos le Grossman du Tout passe (1963) pour expliquer la difficulté des communistes fidèles à mettre à distance le projet soviétique (p. 42-43): se satisfaire d'être un copeau, certes. Mais pourquoi accepter qu'on coupe la forêt?

\section{AUTEURS}

MARC ELIE

CERCEC, CNRS-EHESS 